\title{
From lab to clinic
}

Citation for published version (APA):

Jansen, A., Schyns, G., Bongers, P., \& van den Akker, K. (2016). From lab to clinic: Extinction of cued cravings to reduce overeating. Physiology \& Behavior, 162, 174-180.

https://doi.org/10.1016/j.physbeh.2016.03.018

Document status and date:

Published: 01/08/2016

DOI:

10.1016/j.physbeh.2016.03.018

Document Version:

Publisher's PDF, also known as Version of record

Document license:
Taverne

Please check the document version of this publication:

- A submitted manuscript is the version of the article upon submission and before peer-review. There can be important differences between the submitted version and the official published version of record.

People interested in the research are advised to contact the author for the final version of the publication, or visit the DOI to the publisher's website.

- The final author version and the galley proof are versions of the publication after peer review.

- The final published version features the final layout of the paper including the volume, issue and page numbers.

Link to publication

\footnotetext{
General rights rights.

- You may freely distribute the URL identifying the publication in the public portal. please follow below link for the End User Agreement:

www.umlib.nl/taverne-license

Take down policy

If you believe that this document breaches copyright please contact us at:

repository@maastrichtuniversity.nl

providing details and we will investigate your claim.
}

Copyright and moral rights for the publications made accessible in the public portal are retained by the authors and/or other copyright owners and it is a condition of accessing publications that users recognise and abide by the legal requirements associated with these

- Users may download and print one copy of any publication from the public portal for the purpose of private study or research.

- You may not further distribute the material or use it for any profit-making activity or commercial gain

If the publication is distributed under the terms of Article $25 \mathrm{fa}$ of the Dutch Copyright Act, indicated by the "Taverne" license above, 
Review

\title{
From lab to clinic: Extinction of cued cravings to reduce overeating
}

\author{
Anita Jansen *, Ghislaine Schyns, Peggy Bongers, Karolien van den Akker
}

Clinical Psychological Science, Maastricht University, The Netherlands

\section{H I G H L I G H T S}

- Food cue reactivity (FCR) sabotages healthy eating.

- FCR induces weight gain and impedes weight loss (maintenance).

- FCR is easily acquired but the extinction of appetitive responding is difficult.

- Food cue exposure should include new procedures to be more effective.

\section{A R T I C L E I N F O}

\section{Article history:}

Received 10 December 2015

Received in revised form 11 March 2016

Accepted 15 March 2016

Available online 17 March 2016

\section{Keywords:}

Appetitive conditioning

Craving

Overeating

Extinction

Cue exposure

Inhibition

\begin{abstract}
A B S T R A C T
Food cue reactivity is a strong motivation to eat, even in the absence of hunger. Therefore, food cue reactivity might sabotage healthy eating, induce weight gain and impede weight loss or weight maintenance. Food cue reactivity can be learned via Pavlovian appetitive conditioning: It is easily acquired but the extinction of appetitive responding seems to be more challenging. Several properties of extinction make it fragile: extinction does not erase the original learning and extinction is context-dependent. These properties threaten full extinction and increase the risk of full relapse. Extinction procedures are discussed to reduce or prevent the occurrence of rapid reacquisition, spontaneous recovery, renewal and reinstatement after extinction. A translation to food cue exposure treatment is made and suggestions are provided, such as conducting the exposure in relevant contexts, using occasional reinforcement and targeting expectancy violation instead of habituation. A new hypothesis proposed here is that the adding of inhibition training to strengthen inhibition skills that reduce instrumental responding, might be beneficial to improve food cue exposure effects.
\end{abstract}

@ 2016 Elsevier Inc. All rights reserved.

\section{Contents}

1. Introduction . . . . . . . . . . . . . . . . . . . . . . . . . . . . . . . . . . . . . . . . . . . 174

2. Acquisition of food cue reactivity . . . . . . . . . . . . . . . . . . . . . . . . . . . . . . . . . . . . . . 175

3. Extinction of food cue reactivity . . . . . . . . . . . . . . . . . . . . . . . . . . . . . . . . . . . . . . . . 175

4. Dieting and learning. . . . . . . . . . . . . . . . . . . . . . . . . . . . . . . 176

5. Inhibition training. . . . . . . . . . . . . . . . . . . . . . . . . . . . . . . . . . . . . . 176

6. Translation to the clinic: exposure therapy. . . . . . . . . . . . . . . . . . . . . . . . . . . . . . . . . . . 177

Acknowledgements . . . . . . . . . . . . . . . . . . . . . . . . . . . . . . . . . . . . . . 178

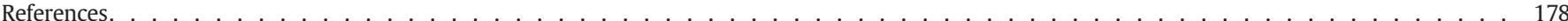

\section{Introduction}

Imagine a table full of your favorite sweet and savory temptations. Imagine the taste of these delicious foods. Imagine that you could eat

\footnotetext{
* Corresponding author.
}

them all without any restrictions. You will probably notice that your mouth is starting to water, and you might feel an intense desire to eat, even though you are unaware of many other physiological preparatory responses, such as insulin release, ghrelin response, stomach secretions, dopamine changes, activation of reward-associated areas in the brain and so on (see e.g., $[21,45,65,72,88])$. These appetitive responses to cues that signal the availability of food are collectively called food cue 
reactivity; the responding prepares the body for food intake and increases one's motivation to eat (e.g., [55]). Food cue reactivity during exposure to tasty foods is a normal and healthy response $[22,43,54$, 55]. However, compared to people without eating concerns, food cue reactivity is significantly stronger in concerned eaters, such as unsuccessful dieters, bulimia nervosa patients, binge eaters and obese people [22, $39,41,49,56,61,73,78,87]$.

Increased food cue reactivity motivates eating, even in the absence of hunger and in excess of calories physically needed, and therefore easily results in overeating and weight gain $[8,10,35,42]$. For example, overweight children demonstrated cued overeating while lean children did not and, in the overweight children, the amount eaten correlated strongly with increased salivary responding during exposure to the food ( $r=0.62$; [39]). Food cue reactivity not only contributes to the maintenance of overeating and weight gain - it also increases the risk of relapse during and after weight loss $[42,43]$. Though there exist individual differences in food cue reactivity [14,50], increased reactivity to food cues usually follows from Pavlovian appetitive conditioning, i.e., associative learning.

\section{Acquisition of food cue reactivity}

Food cue reactivity is easily learned. The early observations of Ivan Petrovich Pavlov are the most well-known: Pavlov observed digestive preparatory responses (e.g., salivation) in response to stimuli that signaled dog food, for example specific sounds or footsteps of the person feeding the dog (see [71]). During Pavlovian conditioning - or associative learning - the organism learns that a neutral stimulus predicts the occurrence of a second stimulus (e.g., the eating of dog food). The neutral stimulus will soon produce the same response in the organism as the second stimulus - in the above mentioned case of Pavlov's dog: salivation. A large number of animal studies show that physiological responses elicited by food intake (e.g. insulin release, blood sugar increase and salivation) can be brought under the control of any stimulus predictive of food intake, such as odors, sounds, lights and time of the day $([10,12,19]$; see $[35,66,68,89,90,92])$. Of interest is that these stimuli also potentiate feeding in sated states $[10,90]$. Context cues are also able to drive consumption: Rats consume significantly more lesspreferred food (chow) when exposed to context cues that were previously paired with the intake of highly palatable foods [4]. Thus, context-cues associated with palatable food intake might drive overeating in rats, even when the rats are sated and when the food is lesspreferred. Cue-conditioned overeating is quickly learned and particularly strong when palatable foods (high in calories, fat, salt and sugar) are involved in the cue - intake associations [4]. All kinds of cues and/ or contexts can be associated with intake and become signals (conditioned stimuli; CS) for consumption (unconditioned stimulus; US).

Similarly, it is relatively easy for humans to learn food cue reactivity and cued eating through associative learning. Very young children (35 years old) demonstrated increased intake and shorter latencies to eat in a context that was associated with eating [3], and undergraduates demonstrated increased salivation responses to neutral cues that they had learned to associate with food consumption [38]. Several recent well-controlled experimental studies show that only four to six associations between a neutral stimulus and actual food intake are necessary to learn that a stimulus predicts intake, after which the mere presence of the food-signaling stimulus is sufficient to elicit eating expectations and desires [6,7,63,75-77,79-82].

Environmental contexts can also act as signals for intake. A virtual reality study used various contexts such as an Italian plaza and a dojo (Japanese room to practice martial arts) to predict milkshake intake, and demonstrated classically conditioned eating desires and salivary responses only in the context that predicted milkshake intake [75]. A daily life analogy is that if one always eats crisps on the couch when viewing one's favorite television series, just sitting on the couch and hearing the theme song of the series might make one crave crisps. Even when one is satiated (e.g., after dinner), the signal that predicts consumption is able to elicit food cravings (i.e., intense desires to eat specific foods) and, therefore, the motivation to eat.

Potentially every stimulus or context can act as a food-predicting signal: food preparing rituals, the seeing, smelling and tasting of foods, interoceptive contexts like physical state (hunger/deprivation, satiety), hormonal state, mood state, expectations, thoughts about foods, physical contexts like a room, specific location, shopping mall, furniture, television, music, computer, and so on. Bongers \& Jansen [7] demonstrated that learning to associate specific mood states with intake caused the eating-related emotions to elicit cued cravings and food selection. A daily life example is the eating of e.g. chocolate (nearly) always when feeling sad (often referred to as 'emotional eating'). When cues or contexts reliably predict intake, they are able to elicit mental representations of the US (food). When confronted with the cue or context (CS), memories of the tasty foods are activated and desires to eat, or food cravings, are triggered - even in the absence of hunger.

To summarize, in our current society, highly rewarding calories are easy-to-get: fast food is available everywhere and most people like it. Palatable high-calorie foods are primary positive reinforcers and have high potential for conditioning. Any time food is ingested, the cues and contexts that are present at the time can become associated with eating $[12,46,69,89]$. Cued cravings are quickly learned. Associative learning will be stronger when the probability relationship between exposure to cues/contexts and reinforcement increases and when the US is more intense (e.g., more calories, higher palatability) [35].

\section{Extinction of food cue reactivity}

Cued cravings might easily sabotage healthy eating. Dieting, losing weight and the maintenance of lost weight will also be more difficult with increasing levels of food cue reactivity. A reduction in reactivity to tempting food cues could eliminate the primary motivation for eating and might facilitate healthy eating, adherence to restrictive diets, weight loss and weight loss maintenance [42,44]. Indeed, obese individuals who have successfully lost weight salivated significantly less during food cue exposure compared to unsuccessful obese dieters [5,41]. Though these studies were correlational, they indirectly support the idea that decreased cue reactivity is associated with successful dieting and weight loss. Therefore, a key question is: How can food cue reactivity - including food cravings - be effectively extinguished?

Pavlovian learning theory posits that Pavlovian extinction is the royal road to learn that a cue or context predicts no longer predicts intake. During a most straightforward Pavlovian extinction procedure, the cue or context that once signaled intake remains systematically unreinforced, i.e., the associated tasty foods are no longer eaten. Consequently, cue reactivity or learned appetitive responding should diminish [42]. When a person is on a restrictive diet during which he is exposed to all kinds of food cues but he does not eat (i.e. he is not reinforcing the cues that signal eating), his cue reactivity should, in the end, extinguish. However, this may take a while and as long as the person remains cue reactive his dieting efforts are easily undermined [77]. In addition to natural extinction by restrictive dieting being a lengthy process, many dieters do not expose themselves to powerful foodsignaling cues as long as they are on a diet [42]. This avoidance behavior is especially characteristic of typical diets in which people only drink shakes or are highly selective in their food choices. These diets do not enable cue reactivity to extinguish, as these people avoid learning that the food-signaling cue does not predict intake. For successful dieting and a reduction of overeating, decreased cue reactivity seems necessary. But even when cue reactivity successfully extinguishes, food cue reactivity can easily return. Bouton [11-13,26] discusses several properties of extinction that make it fragile: Extinction does not erase the original learning and extinction is context-dependent. These properties threaten full extinction and increase the risk of relapse. 
Extinction is not unlearning. Extinction is not simply the forgetting or unlearning of an existing cue - intake association. Instead, extinction adds a new memory to the existing one: During extinction, the individual gradually learns that the cue (CS) might also predict no US, no eating. For example, when feeling sad predicts the eating of chocolate, the cue signaling intake (feeling sad) is systematically unreinforced during extinction, i.e., sad moods will be induced while the associated chocolate is no longer eaten. In this way, one will learn during extinction that feeling sad is no longer a predictor of eating chocolate. However, the old association of feeling sad - eating chocolate is not erased but still exists and can be easily re-activated. Therefore, after extinction, the CS is ambiguous, it signals two possible USs: eating or not eating. Thus, extinction is inhibitory learning of the original CS - US association and not unlearning. The original association still exists and, if activated, appetitive responding might return and a lapse or relapse may occur.

Extinction is context-dependent. Whereas the acquisition of CS - US associations readily generalizes, extinction is largely context dependent. Context is a broad concept: It includes exteroceptive background cues like the physical environment as well as interoceptive cues such as mood states, hormonal states, states of deprivation (hunger or satiety), drug states, time, passage of time and specific thoughts [12,13]. An ambiguous CS (after extinction) will trigger different responses in different contexts; in some contexts an extinguished CS does not evoke desire to eat, whereas in others it can trigger intense food cravings [13]. One implication of context-dependent extinction is that a return of cue reactive responding is possible when the context changes. Many animal studies demonstrate spontaneous recovery, renewal, reinstatement and rapid reacquisition after extinction, which show that the original learning is still held in memory and context-dependent [12]. Spontaneous recovery might occur when time elapses after extinction; with the passing of time after extinction, the original responding (food cue reactivity) can return. In renewal, food cue reactivity returns when the cue (CS) is presented in a different context than the extinction context. For example, when the CS - US association is successfully extinguished in the therapist's room, confrontation with the CS at home might renew food cue reactivity or food cravings. Reinstatement may occur when one is confronted again with the US after extinction, e.g., when one eats a piece of chocolate after extinction. The eating (US) reinstates responding to the CS. Rapid reacquisition is the quick return of fullblown responding to the CS when some CS - US pairings are repeated after extinction. For example, after successful extinction and a period of abstinence one again eats crisps (US) when watching one's favorite TV shows (CS). This so-called 'lapse' might easily result in a full-blown return of food cue reactivity and relapse [77]. Therefore, extinction procedures that reduce or prevent the occurrence of rapid reacquisition, spontaneous recovery, renewal and reinstatement after extinction are necessary to prevent full relapse. How can extinction procedures be optimized?

\section{Dieting and learning}

Diets differ in many respects. For example, some diets are very strict and rigid, while others are more flexible. Some people just try to eat less of many food items during regular meals, others only drink shakes, and others skip meals, and so on. Although we do not know much about behavioral dieting strategies, people who lost weight successfully do report that they are continually strict dieters who show little variety in their diets [25,64,91].

In line with these findings, Van den Akker et al. [76,78] proposed that dieters who frequently alternate restriction and eating in response to food cues may develop a learning schedule (partial reinforcement) that results in a slowed extinction of food cue reactivity (partial reinforcement extinction effect) and a greater difficulty to diet successfully. Strict dieting may prevent the development of partial reinforcement schedules, facilitating subsequent extinction. Such differences in learning histories may also explain inter-individual differences in dieting success to some extent.

However, learning principles also predict that some flexibility in dieting can have beneficial effects by tackling rapid reacquisition of appetitive responding. The occasional reinforcement of a CS during acquisition and extinction was found to result in less rapid responding during reacquisition in humans, meaning that reacquisition (or relapse in clinical terms) was slower [76-78]. Occasionally cued eating during acquisition [76,78] or extinction [77] slowed down the extinction of expectancies and desires and also reduced the speed of the reacquisition of expectancies, but not eating desires. The slower extinction was specific for reinforcement of the CS - US bond and not due to mere eating (a control condition received unpaired (CS unrelated) intake and showed normal extinction). The delayed reacquisition of expectancies was explained as follows: Occasionally reinforced trials enable reinforced trials (cued intake) to be associated with extinction trials which could lead to more generalization between extinction and reacquisition contexts, thereby slowing reacquisition [77]. Thus, during occasional reinforced extinction, one learns that a reinforced cue might mean that the next trials will not be reinforced. In other words, eating in response to a cue does not automatically mean that additional reinforcements follow. Many dieters are inclined to think "I have blown my diet, I might as well continue to eat," after a one-off diet break, e.g., by eating chocolate when feeling sad despite good intentions to not eat the chocolate in a sad mood. Then the incidental CS - US reinforcement is followed by relapse (binge eating or quitting the diet completely). The learning of occasionally reinforced trials might protect against this diet-breaking "what-the-hell effect"; the occasional reinforcement findings imply that dieters would benefit from occasional lapses in their diet because they learn that one reinforced cue ("lapse") does not mean that all cues will be reinforced or even that a reinforced cue means that following cues are not reinforced [77]. Occasional reinforcement (lapses) will only be helpful when followed by new restriction; in occasionally reinforced extinction trials, one learns that lapses are infrequent and do not mean a full relapse. The eating of one snack might have become a cue for having a full-blown binge in binge eaters. Binge eating will be reduced when the person learns to associate the eating of one snack with no additional intake (occasional reinforcement). The counterintuitive conclusion is that during dieting (extinction), occasionally eating 'forbidden' foods (US) in response to a food-signaling cue (CS) is actually helpful for achieving full abstinence.

An interesting question here is how large the US should be in occasional reinforcement. Experimental studies [76-78] generally use small bites of chocolate mousse, whereas real USs of unsuccessful dieters or binge eaters usually concern large amounts of food. Also, one bite of a forbidden food (priming dose, appetizer, preload) is often experienced as a signal or cue for uncontrolled or disinhibited intake in dieters. These dieters should thus learn to associate the eating of a small appetizer with no further eating (unreinforced trial), and sometimes they should associate the eating of an appetizer with more eating (reinforced trial). The studies of Van den Akker et al. [76-78] also suggest that it might be beneficial to provide USs unpaired from their CSs. Likewise, Jansen [35, p263] suggested eating moderate amounts of binge foods (US) under conditions that do not cue a binge, for example in contexts in which one would never overeat. It is an exciting empirical question whether occasional reinforcement and unpaired intake (US without (S) will reduce overeating in clinical samples.

\section{Inhibition training}

Extinction is inhibitory learning and not unlearning, suggesting that extinction might be related to one's ability to inhibit responding. Extinction procedures might therefore be more effective with stronger inhibition skills, while they might be less effective with weaker inhibition skills. One study in our lab indeed demonstrated that participants with weak inhibition skills show worse extinction of appetitive 
responses compared to participants with stronger inhibition skills ([76, 78]; but see [63]). This is especially worth mentioning because a robust finding is that obesity and overeating are associated with weak inhibition skills (e.g., [24,27-33,40,51,57-60]) especially when obese individuals are low in restraint [67]. It has been suggested that overeating follows in particular from a lack of inhibitory control over the hedonic, appetitive system (see e.g., [2,31-33,40]), which makes it difficult to refrain from (over)eating in tempting situations. In other words, people with weak inhibition skills usually show low eating restraint might need extinction procedures to extinguish their heightened food cue reactivity and appetitive responding, but they profit less from extinction procedures because they have weak inhibition skills. It is a new and interesting idea to test whether a simultaneous strengthening of inhibition skills would enhance extinction effects during food cue exposure.

A series of studies into the effects of a computerized training to inhibit responses to food stimuli, using the Go-NoGo task, systematically shows reduced desires to eat and decreased snack intake ([27,32,33, $47,83,84$ ]; but see also [1]), and some studies even show reduced body weight following relatively short inhibition training $[48,85]$. During the Go-NoGo inhibition training, participants learn to respond to neutral stimuli or healthy foods (Go) while inhibiting responses to unhealthy foods (NoGo). The computer training consists of hundreds of trials in which the participant has to respond as quickly as possible (to healthy foods or neutral stimuli) - or to inhibit responding (to high calorie foods). Such training is effective in weakening operant responding.

In a recent study, Houben and Jansen [33] showed that the foodspecific inhibition training induced automatic inhibition associations, which facilitated inhibitory control over food-related urges. It would be exciting to test in future studies whether inhibitory learning during exposure is enhanced - and exposure is more effective - when executive functioning and related cortical regions are activated and strengthened. This could be done by adding a Go-NoGo training to the exposure (to strengthen inhibition skills and learn inhibition associations; e.g., [33]) or by adding other innovative interventions, like the administration of the pharmacological agent D-cycloserine (which facilitates inhibitory learning; [62]) or transcranial electrical brain stimulation as a noninvasive cortical stimulation technique that improves learning [15]. Another fascinating way to weaken operant responding could be the use of imagery. Just imagining consuming specific foods ( $\mathrm{M} \& \mathrm{M}$ 's, cheese) by performing repetitive actions to bring the imagined food to one's mouth (no actual food, no actual eating) decreased desires to eat and actual consumption [53]. The study shows that repeatedly simulating the act of eating without actual eating (i.e., without reinforcement) leads to decreased desires and decreased intake. In other words, repeated nonreinforcement of an eating response might lead to a suppression of actual eating behavior.

\section{Translation to the clinic: exposure therapy}

The clinical analogue of extinction is exposure with response prevention, a well-known behavioral intervention during which participants are repeatedly exposed to unreinforced cues. Exposure therapy has been applied in anxiety disorders for many decades and appears to be effective in reducing fear and avoidance behavior. A translation to addictive disorders (e.g., [20]) and eating disorders (e.g., [34-36]) was made several decades ago. The food cue exposure with response prevention aims to extinguish food cue reactivity and decrease cued overeating.

A recent neuroimaging study showed that prolonged food cue exposure (smelling chocolate) without eating leads to reduced rewardrelated activity in the chocolate lover's brain [23], and several clinical pilot studies show that food cue exposure with response prevention is highly effective in the reduction of craving and binge frequency in bulimia nervosa patients $[36,37,52,74]$. Two of these studies even showed that food cue exposure was highly effective in the reduction of binge eating in adult and adolescent eating disorder patients who showed no or poor response to evidence-based treatments of choice, including cognitive behavior therapy $[52,74]$. The positive findings from these pilot studies suggest that cue exposure might be an effective treatment for binge eaters. Note, however, that although the data are promising, they come from pilot studies with small sample sizes $[36,37,74]$ or no control group [52].

More recently, the effect of food cue exposure was studied in overweight and obese children [9] and overweight and obese adults [70]. Boutelle et al. [9] delivered eight weekly sessions of food cue exposure or appetite awareness training (control group). Only the food cue exposure was effective in reducing eating in the absence of hunger. Though self-reported overeating episodes were significantly reduced in both conditions, BMI was increased at follow ups. Schyns et al. [70] studied a single-session ( $80 \mathrm{~min}$ ) of food cue exposure vs. a control intervention and found that the food cue exposure intervention was effective in decreasing ad lib intake of the exposed food item during a taste test performed in the absence of hunger. Thus, food cue exposure seems to be a promising intervention for binge eaters and overweight/obese people, though more powerful studies and research on long term effects are needed: Is exposure indeed effective in the prevention of relapse?

Older food cue exposure manuals (e.g., [35-37]) aim at the habituation of food cravings though some anxiety researchers $[17,18]$ recently demonstrated that habituation is not a good predictor of treatment outcome in anxiety studies [16]. It is argued that the violation of CS - US expectancies during exposure is more important for its effectiveness than the habituation of anxiety [18].

Translated to eating disorders, beliefs like "If I am alone at home with a box of chocolate, I will eat it all within an hour", "If I eat one bite, I will eat it all," or "I will panic if I do not eat" should be violated during exposure. The belief is violated, for example, when one succeeds in being at home alone for an hour without eating, when taking one bite without eating it all, or when there is no panic attack even though one did not eat.

In line with the findings on anxiety from Craske's lab, Schyns et al. [70]) showed that within-session habituation of cue reactivity (craving and salivation) did not correlate with food intake after prolonged exposure, whereas a significant correlation was found between the violation of expectancies and intake: Participants who successfully reduced their belief in "If CS then US" expectancies such as 'If I have tasty foods in front of me, then I cannot resist eating them' ate significantly less of the foods they were exposed to than participants whose beliefs were not reduced.

Based on the new insights into extinction discussed in this paper, we propose some techniques that might improve current exposure for overeaters in clinical practice:

1. Do exposure in the overeating context

When exposure is done in treatment settings, it is predicted that when a patient returns to the original (over)eating context, renewal will take place. The original context will still trigger strong cravings and the original behavior (i.e., overeating) or (re)lapse. For clinical practice, this means that extinction should be done in the contexts that best predict overeating. It is important to note that contexts are not restricted to physical places, like a specific room or shopping mall. They can also include specific furniture, watching television, using the computer and several interoceptive contexts like physical states (hunger/ deprivation, satiety), hormonal states, mood states, expectations, thoughts about foods, and so on. As many cues and contexts as possible should be used in the exposure sessions; they can be used in isolation but also in diverse combinations. Two of our pilot studies [36-38] exposed overeaters in their overeating context (including but not limited to the physical context) and two larger studies using context exposure are now running in our lab. An alternative is the use of retrieval cues, though, to our knowledge, there are no well-controlled data available on the effectiveness of retrieval cues.

2. Repeat exposure frequently

The learning of new inhibitory pathways (CS means no US) is fragile at the start of exposure therapy. After exposure therapy, the CS is ambiguous and signals two possible USs: (over)eating or no (over)eating. 
The original association still exists and, if activated, the appetitive responding returns and a lapse or relapse might occur. As long as the original memory is strong and easily activated, relapse is possible. One way to strengthen the new CS - no US memory, and to make it stronger than original CS - US memory, is to do frequent exposures and to include exposure homework in treatment. Frequent exposures might also reduce the risk of spontaneous recovery. Further, repeating the exposures might strengthen the consolidation of new CS - no US memories learned during treatment [70].

3. Eat 'favorite foods' under conditions that do not cue overeating

One risk for relapse is reinstatement that may occur when confronted with the US after extinction, e.g., when one eats favorite foods after extinction when cues or contexts are not present. The eating of favorite foods (US) could reinstate one's responding to the CS. During the exposure intervention, the individual should practice eating some 'favorite foods' (US) when the CS is not present (unpaired), for example eating them in contexts that would not quickly be associated with overeating. Jansen [35] suggests eating small amounts of 'favorite foods' a number of times during the therapy under conditions that do not cue overeating, for example at work amongst colleagues, or with the therapist in a cafe. Jansen [35] also proposes to install moments of 'alternative overeating'. The alternative overeating can be used if the urge to eat is irresistible. A normal overeating episode reinforces the link between cues and overeating, while the alternative overeating will not. For all cues and contexts, a clearly different but attractive alternative should be chosen. One might think of eating some nice cookies in the bathroom instead of eating one's favorite ice cream on the couch while watching television. Once an alternative overeating episode has been used, a new one is designed (e.g., eating some nuts in the garage). The alternative overeating episode is discussed in detail in advance and put in writing (flash cards) to make it easier to use. In this way, reinstatement can be prevented.

4. Eat 'favorite foods' under conditions that do cue overeating

Another risk for relapse is the quick return of responding to the CS when a CS - US pairing is repeated after extinction (= rapid reacquisition). For example, if, after successful extinction, one overeats (US) again when confronted with a cue or context (CS) that used to predict overeating, a full-blown relapse is possible. Occasionally reinforcing the CS during extinction slows reacquisition (relapse) [77]. During exposure, the individual can practice eating some of the 'favorite foods' (US) when confronted with the CS. Disconfirmation of the belief that the "CS means US" (a full blown overeating episode or 'always' overeating) at the same time could be helpful to prevent relapse [70].

5. Violate "If CS, then US" beliefs

Habituation appears to be less important for the success of exposure than disconfirmation of "If CS, then US" beliefs. Strong, frequent and repeated violation of those beliefs does strengthen the learning of CS - no US associations [18]. The length of an exposure session can be determined by the time needed for US expectancies to be violated (instead of waiting for the craving to decrease) [18]. For example, beliefs like "If I am alone at home with a box of chocolate, I will eat it all" or "If I eat one bite, I will eat it all" will be violated if the individual does not eat the entire box, or if only one bite is taken. "I will panic if I do not eat" is violated when there is no panic attack while not eating, "If I do not eat sweets when I travel home after work, I will pass out in the train" will be violated when travelling home by train succeeds without eating and without passing out. The violation of these beliefs, which do maintain the undesired eating, seems to be important for effective exposure. Violation can be done by asking how big the chance is that the "If CS, then US" belief will happen during the exposure, and how long it will take to occur. For instance, when one predicts that eating the entire box of chocolate will occur within $10 \mathrm{~min}$, the belief will be disconfirmed after 10 min of exposure. Thus, the end of an exposure session is guided by the time needed for disconfirmation of the belief, not by the time needed for habituation.

6 . Add inhibition training
A simultaneous strengthening of inhibition skills and inhibitory learning may enhance extinction effects during food cue exposure. This could be done by adding Go-NoGo training, the administration of D-cycloserine, transcranial electrical brain stimulation or the use of imagery (e.g., performing repetitive actions to bring an imagined food to one's mouth). It should be noted that it has not yet been studied whether adding these inhibition techniques indeed improves exposure effects.

To conclude, food cue reactivity motives overeating and weight gain and impedes weight loss (maintenance). Food cue reactivity is easily learned but the extinction of appetitive responding is challenging. Food cue exposure treatment might benefit from new insights from the anxiety disorders field that can be translated into procedures to improve the extinction of learned food cue reactivity, like doing the exposure in relevant contexts, the using of occasional reinforcement, and expectancy violation. We propose that adding inhibition training can improve exposure effects by strengthening inhibition skills and thereby reducing instrumental responding. There is a lot of room for new research that is valuable for improving eating disorder and obesity treatments.

\section{Acknowledgements}

This manuscript is based on work presented in a MARS lecture at the Annual Meeting of the Society for the Study of Ingestive Behavior in Denver, July 7-11, 2015.

This work is supported by the Netherlands Organisation for Scientific Research (NWO): Vici Grant 453.10.006, awarded to Anita Jansen. We are grateful to Jessica M. Alleva for her help.

\section{References}

[1] V. Allom, B. Mullan, Two inhibitory control training interventions designed to improve eating behaviour and determine mechanisms of change, Appetite 89 (2015) 282-290.

[2] B.M. Appelhans, Neurobehavioral inhibition of reward-driven feeding: implications for dieting and obesity, Obesity 17 (2009) 640-647.

[3] L.L. Birch, L. McPhee, S. Sullivan, S. Johnson, Conditioned meal initiation in young children, Appetite 13 (1989) 105-113.

[4] M.M. Boggiano, J.R. Dorsey, J.M. Thomas, D.L. Murdaugh, The Pavlovian power of palatable food: lessons for weight-loss adherence from a new rodent model of cue-induced overeating, Int. J. Obes. 33 (2009) 693-701.

[5] D.S. Bond, H.A. Raynor, J.M. McCaffery, R.R. Wing, Salivary habituation to food stimuli in successful weight loss maintainers, obese and normal-weight adults, Int. J. Obes. 34 (2010) 593-596.

[6] P. Bongers, K. van den Akker, R. Havermans, A. Jansen, Emotional eating and Pavlovian learning: does negative mood facilitate appetitive conditioning? Appetite 89 (2015) 226-236.

[7] P. Bongers, A. Jansen, Emotional eating and Pavlovian learning: evidence for conditioned appetitive responding to negative emotional states, Cognition and Emotion (2015), http://dx.doi.org/10.1080/02699931.2015.1108903 Online published 5 November.

[8] R. Boswell, H. Kober, Food cue reactivity and craving predict eating and weight gain: a meta-analytic review, Obes. Rev. 17 (2016) 159-177.

[9] K.N. Boutelle, N.L. Zucker, C.B. Peterson, S.A. Rydell, G. Cafri, L. Harnack, Two nove treatments to reduce overeating in overweight children: a randomized controlled trial, J. Consult. Clin. Psychol. 79 (2011) 759-771, http://dx.doi.org/10.1037/ a0025713.

[10] K.N. Boutelle, M.E. Bouton, Implications of learning theory for developing programs to decrease overeating, Appetite 93 (2015) 62-74.

[11] M.E. Bouton, Context, ambiguity, and unlearning: sources of relapse after behavioral extinction, Biol. Psychiatry 52 (10) (2002) 976-986, http://dx.doi.org/10.1016/ s0006-3223(02)01546-9.

[12] M.E. Bouton, Learning and the persistence of appetite: extinction and the motivation to eat and overeat, Physiol. Behav. 103 (2011) 51-58, http://dx.doi.org/10.1016/j. physbeh.2010.11.025.

[13] M.E. Bouton, D. Swartzentruber, Sources of relapse after extinction in Pavlovian and instrumental learning, Clin. Psychol. Rev. 11 (2) (1991) 123-140, http://dx.doi.org/ 10.1016/0272-7358(91)90091-8

[14] S. Carnell, C.M.A. Haworth, R. Plomin, J. Wardle, Genetic influence on appetite in children, Int. J. Obes. 32 (2008) 1468-1473.

[15] B.A. Coffman, V.P. Clark, R. Parasuraman, Battery powered thought: enhancement of attention, learning, and memory in healthy adults using transcranial direct current stimulation, Neurolmage 85 (2014) 895-908. 
[16] M.G. Craske, K. Kircanski, M. Zelikowsky, J. Mystkowski, N. Chowdhury, A. Baker, Optimizing inhibitory learning during exposure therapy, Behav. Res. Ther. 46 (1) (2008) 5-27, http://dx.doi.org/10.1016/j.brat.2007.10.003.

[17] M.G. Craske, B. Liao, L. Brown, B. Vervliet, The role of inhibition in exposure therapy, Journal of Experimental Psychopathology 3 (3) (2012) 322-345, http://dx.doi.org/ 10.5127/jep.026511.

[18] M.G. Craske, M. Treanor, C.C. Conway, T. Zbozinek, B. Vervliet, Maximizing exposure therapy: an inhibitory learning approach, Behav. Res. Ther. 58 (2014) 10-23, http:// dx.doi.org/10.1016/j.brat.2014.04.006.

[19] R. Deutsch, Conditioned hypoglycemia: a mechanism for saccharin-induced sensitivity to insulin in the rat, J. Comp. Physiol. Psychol. 86 (1974) 350-358.

[20] D.C. Drummond, S. Glautier, A controlled trial of cue exposure treatment in alcohol dependence, J. Consult. Clin. Psychol. 62 (1994) 809-817.

[21] M. Feldman, C.T. Richardson, Role of thought, sight, smell, and taste of food in the cephalic phase of gastric acid secretion in humans, Gastroenterology 90 (1986) 428-433.

[22] D. Ferriday, J.M. Brunstrom, 'I just can't help myself': effects of food-cue exposure in overweight and lean individuals, Int. J. Obes. 35 (2011) 142-149.

[23] A. Frankort, A. Roefs, N. Siep, A. Roebroeck, R. Havermans, A. Jansen, The craving stops before you feel it: neural correlates of chocolate craving during cue exposure with response prevention, Cereb. Cortex 24 (2014) 1589-1600.

[24] R. Guerrieri, C. Nederkoorn, A. Jansen, The interaction between impulsivity and varied food environment: its influence on food intake and overweight, Int. J. Obes. 32 (2008) 708-714.

[25] A.A. Gorin, S. Phelan, R.R. Wing, J.O. Hill, Promoting long-term weight control: does dieting consistency matter? Int. J. Obes. 28 (2004) 278-281, http://dx.doi.org/10. 1038/sj.ijo.0802550.

[26] R. Havermans, A. Jansen, Increasing the efficacy of cue exposure treatment in preventing relapse of addictive behavior, Addict. Behav. 28 (2003) 989-994.

[27] K. Houben, A. Jansen, Training inhibitory control: a recipe for resisting sweet temptations, Appetite 56 (2011) 345-349.

[28] K. Houben, R.W. Wiers, A. Jansen, Getting a grip on drinking behavior: training working memory to reduce alcohol abuse, Psychol. Sci. 22 (2011) 968-975.

[29] K. Houben, C. Nederkoorn, R.W. Wiers, A. Jansen, Resisting temptation: decreasing alcohol-related affect and drinking behavior by training response inhibition, Drug Alcohol Depend. 116 (2011) 132-136.

[30] K. Houben, R.C. Havermans, C. Nederkoorn, A. Jansen, Beer à No-Go: learning to stop responding to alcohol cues reduces alcohol intake via reduced affective associations rather than increased response inhibition, Addiction 107 (2012) 1280-1287.

[31] K. Houben, A. Jansen, Lacking skills to improve self-control: reward-induced loss of inhibitory control and overeating in restrained eaters, Journal of Experimental Psychopathology 5 (1) (2014) 29-37.

[32] K. Houben, C. Nederkoorn, A. Jansen, Eating on impulse? The relation between overweight and food-specific inhibitory control, Obesity 22 (2014) E6-E8

[33] K. Houben, A. Jansen, Chocolate equals stop. Chocolate-specific inhibition training reduces chocolate intake and go associations with chocolate, Appetite 87 (2015) 318-323.

[34] A. Jansen, Binge eating: notes and data, Doctoral Dissertation (PhD Thesis), Datawyse, Maastricht, 1990 ISBN 9052910278.

[35] A. Jansen, A learning model of binge eating: cue reactivity and cue exposure, Behav. Res. Ther. 36 (1998) 257-272.

[36] A. Jansen, M. van den Hout, C. van Loof, J. Zandbergen, E. Griez, A case of bulimia successfully treated with cue exposure, J. Behav. Ther. Exp. Psychiatry 20 (1989) 327-332.

[37] A. Jansen, J. Broekmate, M. Heymans, Cue exposure vs self-control in the treatment of binge eating: a pilot study, Behav. Res. Ther. 30 (1992) 235-241.

[38] A. Jansen, B. Boon, H. Nauta, M. van den Hout, Salivation discordant with hunger, Behav. Res. Ther. 30 (1992) 163-166.

[39] A. Jansen, N. Theunissen, K. Slechten, C. Nederkoorn, S. Mulkens, A. Roefs, Overweight children overeat after exposure to food cues, Eat. Behav. 4 (2003) 197-209.

[40] A. Jansen, C. Nederkoorn, L. van Baak, C. Keirse, R. Guerrieri, R. Havermans, Highrestrained eaters only overeat when they are also impulsive, Behav. Res. Ther. 47 (2009) 105-110.

[41] A. Jansen, S. Stegerman, A. Roefs, C. Nederkoorn, R. Havermans, Decreased salivation to food cues in formerly obese successful dieters, Psychother. Psychosom. 79 (2010) 257-258, http://dx.doi.org/10.1159/000315131.

[42] A. Jansen, R. Havermans, C. Nederkoorn, Cued overeating, in: V.R. Preedy, R.R. Watson, C.R. Martin (Eds.), The International Handbook of Behavior, Diet and Nutrition, Springer, New York 2011, pp. 1431-1443.

[43] A. Jansen, Ch. Nederkoorn, A. Roefs, P. Bongers, T. Teugels, R. Havermans, The proof of the pudding is in the eating: is the DEBQ - external eating scale a valid measure of external eating? Int. J. Eat. Disord. 44 (2011) 164-168.

[44] A. Jansen, K. Houben, A. Roefs, A cognitive profile of obesity and its translation into new interventions, Front. Psychol. 6 (2015) 1807, http://dx.doi.org/10.3389/fpsyg. 2015.01807.

[45] W.G. Johnson, H.E. Wildman, Influence of external and covert food stimuli on insulin secretion in obese and normal persons, Behav. Neurosci. 97 (1983) $1025-1028$

[46] D.A. Kessler, The End of Overeating. Taking Control of the Insatiable American Appetite, Rodale, New York, 2009.

[47] N.S. Lawrence, F. Verbruggen, S. Morrison, R.C. Adams, C.D. Chambers, Stopping to food can reduce intake. Effects of stimulus-specificity and individual differences in dietary restraint, Appetite 85 (2015) 91-103.

[48] N.S. Lawrence, J. O'Sullivan, D. Parslowa, M. Javaid, R.C. Adams, C.D. Chambers, K. Kos, F. Verbruggen, Training response inhibition to food is associated with weight loss and reduced energy intake, Appetite 95 (2015) 17-28.
[49] T. Legenbauer, C. Vögele, H. Rüddel, Anticipatory effects of food exposure in women diagnosed with bulimia nervosa, Appetite 42 (2004) 33-40.

[50] C. Llewellyn, J. Wardle, Behavioral susceptibility to obesity: Gene-environment interplay in the development of weight, Physiol. Behav. 152 (2015) 494-501, http:// dx.doi.org/10.1016/j.physbeh.2015.07.006.

[51] A.A. Martin, T.L. Davidson, Human cognitive function and the obesogenic environment, Physiol. Behav. 136 (2014) 185-193.

[52] E. Martinez-Mallén, J. Castro-Fornieles, L. Lázaro, E. Moreno, A. Morer, E. Font, J. Julien, M. Vila, J. Toro, Cue exposure in the treatment of resistant adolescent bulimia nervosa, Int. J. Eat. Disord. 40 (2007) 596-601.

[53] C.K. Morewedge, Y.E. Huh, J. Vosgerau, Thought for food: imagined consumption reduces actual consumption, Science 330 (2010) 1530-1533.

[54] C. Nederkoorn, F. Smulders, A. Jansen, Cephalic phase responses, craving and food intake in normal subjects, Appetite 35 (2000) 45-55.

[55] C. Nederkoorn, A. Jansen, Cue reactivity and regulation of food intake, Eat. Behav. 3 (2002) 61-72

[56] C. Nederkoorn, F. Smulders, R. Havermans, A. Jansen, Exposure to binge food in bulimia nervosa: finger pulse amplitude as a potential measure of urge to eat and predictor of food intake, Appetite 42 (2004) 125-130.

[57] C. Nederkoorn, F.T.Y. Smulders, H. Havermans, A. Roefs, A. Jansen, Impulsivity in obese women, Appetite 47 (2006) 253-256.

[58] C. Nederkoorn, E. Jansen, S. Mulkens, A. Jansen, Impulsivity predicts overweight and treatment outcome in obese children, Behav. Res. Ther. 45 (2006) 1071-1075.

[59] C. Nederkoorn, C. Braet, Y. van Eijs, A. Tanghe, A. Jansen, Why obese children cannot resist food: the role of impulsivity, Eat. Behav. 7 (2006) 315-322.

[60] C. Nederkoorn, R. Guerrieri, R.C. Havermans, A. Roefs, A. Jansen, The interactive effect of hunger and impulsivity on food intake and purchase in a virtual supermarket, Int. J. Obes. Relat. Metab. Disord. 33 (2009) 905-912.

[61] P. Neudeck, I. Florin, B. Tuschen-Caffier, Food exposure in patients with bulimia nervosa, Psychother. Psychosom. 70 (2001) 193-200.

[62] M.M. Norberg, J.H. Krystal, D.F. Tolin, A meta-analysis of $D$-cycloserine and the facilitation of fear extinction and exposure therapy, Biol. Psychiatry 63 (2008) 1118-1126.

[63] H. Papachristou, C. Nederkoorn, S. Beunen, A. Jansen, Dissection of appetitive conditioning: does impulsivity play a role? Appetite 69 (2013) 46-53.

[64] S. Phelan, R.R. Wing, H.A. Raynor, J. Dibello, K. Nedeau, W. Peng, Holiday weight management by successful weight losers and normal weight individuals, J. Consult. Clin. Psychol. 76 (2008) 442-448

[65] M.L. Power, J. Schulkin, Anticipatory physiological regulation in feeding biology, Appetite 50 (2008) 194-206.

[66] T. Powley, The ventromedial hypothalamic syndrome, satiety and a cephalic phase hypothesis, Psychol. Rev. 84 (1977) 89-126.

[67] M. Price, M. Lee, S. Higgs, Food-specific response inhibition, dietary restraint and snack intake in lean and overweight/obese adults: a moderated-mediation model, Int. J. Obes. (2015), http://dx.doi.org/10.1038/ijo.2015.235 Advance Online Publication, 22 December.

[68] J. Rodin, Insulin levels, hunger, and food intake: an example of feedback loops in body weight regulation, Health Psychol. 4 (1985) 1-24.

[69] A.J. Rothman, P. Sheeran, W. Wood, Reflective and automatic processes in the initiation and maintenance of dietary change, Ann. Behav. Med. 38 (S1) (2009) 4-17.

[70] G. Schyns, A. Roefs, S. Mulkens, A. Jansen, Expectancy violation, reduction of food cue reactivity and less eating in the absence of hunger after one food cue exposure session for overweight and obese women, Behav. Res. Ther. 76 (2016) 57-64.

[71] S. Siegel, B.M.C. Ramos, Applying Laboratory research: drug anticipation and the treatment of drug addiction, Exp. Clin. Psychopharmacol. 10 (2002) 162-183.

[72] C. Simon, J.L. Schlienger, R. Sapin, M. Imler, Cephalic phase insulin secretion in relation to food presentation in normal and overweight subjects, Physiol. Behav. 36 (1986) 465-469.

[73] A. Tetley, J. Brunstrom, P. Griffiths, Individual differences in food-cue reactivity. The role of BMI and everyday portion-size selections, Appetite 52 (2009) 614-620.

[74] J. Toro, M. Cervera, M.H. Feliu, N. Garriga, M. Jou, E. Martinez, E. Toro, Cue exposure in the treatment of resistant bulimia nervosa, Int. J. Eat. Disord. 34 (2003) 227-234, http://dx.doi.org/10.1002/eat.10186.

[75] K. Van den Akker, A. Jansen, F. Frentz, R. Havermans, Impulsivity makes more susceptible to overeating after contextual appetitive conditioning, Appetite 70 (2013) 73-80.

[76] K. Van den Akker, R.C. Havermans, M.E. Bouton, A. Jansen, How partial reinforcement of food cues affects the extinction and reacquisition of appetitive responses: a new model for dieting success? Appetite 81 (2014) 242-252.

[77] K. Van den Akker, R.C. Havermans, A. Jansen, Effects of occasional reinforced trials during extinction on the reacquisition of conditioned responses to food cues, J. Behav. Ther. Exp. Psychiatry 48 (2015) 50-58.

[78] K. Van den Akker, K. Stewart, E.E. Antoniou, A. Palmberg, A. Jansen, Food cue reactivity, obesity, and impulsivity: are they associated? Current Addiction Reports 1 (2014) 301-308.

[79] D. Van Gucht, D. Vansteenwegen, T. Beckers, O. Van den Bergh, Return of experimentally induced chocolate craving after extinction in a different context. divergence between craving for and expecting to eat chocolate, Behav. Res. Ther. 46 (2008) 375-391.

[80] D. Van Gucht, D. Vansteenwegen, O. Van den Bergh, T. Beckers, Conditioned craving cues elicit an automatic approach tendency, Behav. Res. Ther. 46 (2008) 1160-1169.

[81] D. Van Gucht, F. Baeyens, D. Vansteenwegen, D. Hermans, T. Beckers, Counterconditioning reduces cue-induced craving and actual cue-elicited consumption, Emotion 10 (5) (2010) 688-695. 
[82] D. Van Gucht, F. Baeyens, D. Hermans, T. Beckers, The inertia of conditioned craving does context modulate the effect of counterconditioning? Appetite 65 (2013) $51-57$.

[83] H. Veling, H. Aarts, E.K. Papies, Using stop signals to inhibit chronic dieters' responses toward palatable foods, Behav. Res. Ther. 49 (2011) 771-780.

[84] H. Veling, H. Aarts, W. Stroebe, Using stop signals to reduce impulsive choices for palatable unhealthy foods, Br. J. Health Psychol. 18 (2013) 354-368.

[85] H. Veling, G.M. van Koningsbruggen, H. Aarts, W. Stroebe, Targeting impulsive processes of eating behavior via the internet. Effects on body weight, Appetite 78 (2014) 102-109.

[87] C. Vögele, I. Florin, Psychophysiological responses to food exposure: an experimental study in binge eaters, Int. J. Eat. Disord. 21 (1997) 147-157.
[88] N.D. Volkow, G.-J. Wang, R.D. Baler, Reward, dopamine and the control of food intake: implications for obesity, Trends Cogn. Sci. 15 (2011) 37-46.

[89] J. Wardle, Conditioning processes and cue exposure in the modification of excessive eating, Addict. Behav. 15 (1990) 387-393.

[90] H.P. Weingarten, Conditioned cues elicit feeding in sated rats. A role for learning in meal initiation, Science 220 (4595) (1983) 431-433.

[91] R.R. Wing, J.O. Hill, Successful weight loss maintenance, Annu. Rev. Nutr. 21 (2001) 323-341.

[92] S.C. Woods, The eating paradox. how we tolerate food, Psychol. Rev. 4 (1991) 488-505. 